\title{
Therapeutic Inertia Is a Problem for All of Us
}

Stephen Brunton, Editor-in-Chief

Primary Care Metabolic Group, Los Angeles, CA

Corresponding author: Stephen Brunton, sbrunton@pceconsortium.com

https://doi.org/10.2337/cd19-0009

(C)2019 by the American Diabetes Association. Readers may use this article as long as the work is properly cited, the use is educational and not for profit, and the work is not altered. See http:// creativecommons.org/licenses/by-nc-nd/3.0 for details.

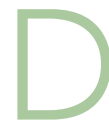

espite the availability of new technologies and therapies, about half of all patients with diabetes in the United States continue to have inadequate glycemic control (1). Why? The reasons are multifactorial; however, therapeutic inertia is a major one.

The term "therapeutic inertia" refers to the failure to advance therapy or to de-intensify therapy when appropriate (2). Why is this important? Many long-term trials show that intensive therapy can have a major impact on cardiovascular morbidity and mortality (3-5). Moreover, achieving early glycemic control may generate a positive legacy effect with persistent reduction in microvascular complications, myocardial infarction, and all-cause mortality $(3,4)$. The EDICT (Efficacy and Durability of Initial Combination Therapy for Type 2 Diabetes) trial showed a significant benefit to early combination therapy compared to a stepwise approach in terms of achievement and persistence of therapeutic goals (6).

Unfortunately, many of us have a "treat to failure" management strategy rather than a "treat to success" approach. In other words, when a patient's A1C becomes inappropriately high, we eventually add a therapeutic agent, and then we wait for the $\mathrm{A} 1 \mathrm{C}$ to rise again significantly before we intervene to add another agent. This approach was characterized in a largescale study of physicians' practices in the real world (7). For patients with an $\mathrm{A} 1 \mathrm{C}>7.5 \%$, it took an average of
1.9 years to intensify treatment by one agent, 7.2 years to add a second agent, and 6.1 years to intensify with a third oral antidiabetic drug (7). Similarly, when patients are initiated on basal insulin, there is a median wait time of 3.7 years to intensification (8). The reasons for these long lag times are innumerable and include provider, patient, and health care system issues.

De-intensification of the therapeutic regimen is also an important aspect of therapeutic inertia (9). We have been taught how and when to add medicines, yet there has been inadequate attention regarding when we should reduce them. At some point, certain therapies may be doing more harm than good. This is especially true in elderly patients for whom aggressive $\mathrm{A} 1 \mathrm{C}$ goals and medications such as sulfonylureas may increase the risk of hypoglycemia and untoward consequences.

In November 2018, I had the opportunity to attend an American Diabetes Association (ADA) summit on therapeutic inertia. With more than 130 representatives of various stakeholder groups in attendance, its goal was to develop a disruptive approach to the problem of therapeutic inertia. The day-long meeting included presentations and discussions and a plan to publish a summary of proceedings and develop pragmatic solutions to this crucial problem during the ensuing 3 years.

The underlying larger purpose of the summit, as explained by ADA Chief Executive Officer Tracey D. 
Brown, MBA, BChE, was "to help patients with diabetes and their families to thrive." This is an admirable goal and one that we can all work toward by actively engaging, partnering, and goal-setting with our patients to assist them in effectively managing their diabetes therapy regimen.

We are eager to learn what the summit produces in terms of initiatives to increase awareness of therapeutic inertia and practical strategies to reduce this significant problem for all of us. Interested parties can keep up with the project as it develops by visiting in the initiative website (professional.diabetes. org/therapeuticinertia). The summit agenda and presentations are already available on the website, and a summary of the proceedings will be posted there soon.

\section{Duality of Interest}

No potential conflicts of interest relevant to this article were reported.

\section{References}

1. Carls G, Huynh J, Tuttle E, Yee J, Edelman SV. Achievement of glycated hemoglobin goals in the US remains unchanged through 2014. Diabetes Ther 2017;8:863-873

2. Khunti K, Davies MJ. Clinical inertia: time to reappraise the terminology? Prim Care Diabetes 2017;11:105-106

3. U.K. Prospective Diabetes Study Group. Effect of intensive blood-glucose control with metformin on complications in overweight patients with type 2 diabetes (UKPDS 34). Lancet 1998;352:854-865

4. Holman RR, Paul SK, Bethel MA, Matthews DR, Neil HA. 10-year follow-up of intensive glucose control in type 2 diabetes. N Engl J Med 2008;359:1577-1589

5. DCCT Research Group. The effect of intensive treatment of diabetes on the development and progression of long-term complications in insulin-dependent diabetes mellitus. N Engl J Med 1993;329:977-986

6. DeFronzo RA, Puckett C, Cersosimo E, Triplitt C, Abdul-Ghani M. Combination therapy with metformin/pioglitazone/ exenatide is superior to sequential add-on therapy in new onset diabetes: 3 -year follow up results of the EDICT study (Poster 794). Presented at the 52nd European Association for the Study of Diabetes annual meeting, Munich, Germany, 12-16 September 2016

7. Khunti K, Wolden ML, Thorsted BL, Andersen M, Davies MJ. Clinical inertia in people with type 2 diabetes: a retrospective cohort study of more than 80,000 people. Diabetes Care 2013;36:3411-3417

8. Khunti K, Nikolajsen A, Thorsted BL, Andersen M, Davies MJ, Paul SK. Clinical inertia with regard to intensifying therapy in people with type 2 diabetes treated with basal insulin. Diabetes Obes Metab 2016;18:401-409

9. Lipska KJ, Ross JS, Miao Y, Shah ND, Lee SJ, Steinman MA. Potential overtreatment of diabetes mellitus in older adults with tight glycemic control. JAMA Intern Med 2015;175:356-362 